\title{
Development of a Transplanting Mechanism Model for Power Operated Rice Transplanter using Graphical Method
}

\author{
Jagjeet Singh* \\ Department of Agricultural \& Food Engineering, Indian Institute of Technology, \\ Kharagpur, West Bengal, 721302, India \\ *Corresponding author
}

\section{A B S T R A C T}

\section{Keywords \\ Prototype, Rice seedling, Seedling finger, Single rowprototype rice transplanter, Transplanting mechanism}

\section{Article Info}

Accepted: 04 November 2018 Available Online: 10 December 2018
Many Chinese and Japanese models are working in India, but these existing models could not become much popular due to some problems like planting more seedlings per hill, complex construction design and more cost. It has been proved an ergonomically, more plants lead to less production. The main aim of this research was to reduce complex construction design and improve accuracy of rice transplanter. Therefore a new transplanting mechanism model was developed for prototype single row rice transplanter. The transplanting mechanism was designed in solid work software after estimating the dimensions of the model using graphical method and then itwas fabricated. This model consists of three sub-assemblies such as transplanting assembly, seedling tray assembly, and main frame. It was tested in laboratory and measured different parameters such as depth of planting, number of seedlings per hill, hill to hill spacing and visible damage were found to be $5.55 \mathrm{~cm}, 2.3,14.43 \mathrm{~cm}$ and 0.05 (out of 2.3 seedlings) respectively. After its satisfactory performance in laboratory, 17 Watt DC motor was fixed to rotate the four bar mechanism and tested in the field. The prototype single row rice transplater was tested in the puddled field of the size $2 \times 1.5 \mathrm{~m}$. Depth of planting, hill to hill spacing, number of seedlings per hill and visible damage were found to be $5.36 \mathrm{~cm}, 18.03 \mathrm{~cm}, 3.57$ and 0.70 per hill respectively. From all these observation, it might be concluded that it was working satisfactorily and it will give an alternative way to design the transplanting mechanism for power operated rice transplanter and help to reduce complexity of constructional design up to certain limit.

\section{Introduction}

Transplanting of the paddy is a very laborious intensive operation. Manual transplanting consumes 300 to 350 man hours per hectare about $25 \%$ of the total labour requirements for the crop (Goel, 2008). Many types of rice transplanters have been developed to reduce the labour requirement problem, timeliness sowing operation, and plant population density, because all these factors directly affect the production of crop. Nowadays, Many Chinese and Japanese rice transplanters are working satisfactorily in India, but these existing models have certain problems like complex constructional design and more number of seedlings per hill. The agronomists recommended the range of spacing between 
hills $(15-17 \mathrm{~cm})$ and optimum number of seedlings (2-3) per hill. However, recommended spacing depends on many factors like verities of seeds, age of seedlings, duration of crop, and type of soils (Alam, 2012 and Wang, 2014).

Use of rice transplanter is limited in India, because more than $60 \%$ farmers come under marginal category, so they are not in position to purchase it. Therefore, there is a need of further research work to reduce constructional complexity and to improve its accuracy. So, little effort was made to develop new transplanting mechanism for prototype single row rice transplanter. The transplanting mechanism is most important component in rice transplanter upon which its performance depend and it consists four bar links with different lengths like crank or driver, follower, coupler and fixed link. The member connects the crank and the follower is known as coupler link and fixed link is the frame. The crank is the shortest link and makes complete revolution. The aim of this research isto develop the transplanting mechanism for power operated single row rice transplanter and tested in laboratory as well as in the field conditions. In this study, more focus was given to design and develop of the mechanism because it affects the performance of rice transplanter.

\section{Materials and methods}

In the present study, the transplanting mechanism was designed and developed by using graphical method for prototype power operated single row rice transplanter.

\section{Selection of profile curve for new transplanting mechanism}

In 1964, Hartenberg and Denavit have drawn more than ten thousand profile curves for four bar mechanism; on the basis of sharpest leaving point and experience, one profile curve was selected which was shown in Figure 1.

After selection of curve, distance PQ, QS, SR, $\mathrm{PR}$ and ST were measured by scale and $15 \mathrm{~mm}$ length was added on both side of the link to drill hole. Some technical specifications of these links are given in Table 1.

\section{Inclination angle of fixed link}

After deciding the length of four links, mild steel material was selected on the basis of availability of the material for these links. These links bolted together using nut and bolts, washer was sandwiched between the links for the free movement of these links and then a pencil was inserted to draw the path travelledbyextension couplerpoint. On the basis of trial, one link fixed at different angle and draw path travel by the exetnsion coupler point. The selected angle of inclination was $60^{\circ}$ for the fixed link, wherethe exetnsion coupler point is lowest point in puddled field, since lowest point is that point where seedlings will planted.

\section{Design of frame}

The fixed link was fixed at an angle $60^{\circ}$ and then crank link was revolved to trace the path of extension coupler point. The height, length and width of the frame were found $625 \mathrm{~mm}$, $825 \mathrm{~mm}$ and $200 \mathrm{~mm}$ respectively. After finding the dimensions of the mechanism, it was framed in solid work software, its top and side view is given below along with all dimensions in $(\mathrm{mm})$.

\section{Fabrication of prototype single row rice transplanter}

The length of four links and dimensions of the frame were estimated from the path traced by the coupler extension point. The mild steel material was selected on the basis of availability of the material for construction of 
these links and frame; however this model was tested in the laboratory and found its satisfactory performance in laboratory. After this, its carrying handle, size of motor and float was estimated. The laboratory model was converted into power operated prototype single row rice transplanter.

This prototype consisted of DC motor (17 Watt), four-bar links, float, frame and a carrying handle. The transplanting mechanism consisted of the four-bar links. The coupler link has a coupler extension point which represented the finger. The fork fixed type finger was fabricated with galvanized iron and fixed in the coupler extension. It has one rectangular shaped groove and the length of the groove was $1.3 \mathrm{~cm}$ decided on basis of its penetration into the seedling tray. The width of slot was calculated on basis of number of seedling required to be picked up (Fig. 2 and $3)$.

\section{Results and discussion}

\section{Displacement analysis}

The analysis was done to establish the relationship between crank angle and links of four bar mechanism by considering the links as vector (Fig. 4). After the analysis, the equations were drawn to know the position of the transplanting finger which is given below.

$$
X_{E}=A B \operatorname{Cos} Q_{1}+B C \operatorname{Cos} Q_{2}+C E \operatorname{Cos} Q_{3} \quad \ldots 1
$$

$$
Z_{8}=A D \sin Q_{4}+C B \sin Q_{3}-C D \sin Q_{3}
$$

When put the value of all parameters in equation 1 and 2 and then the position of transplanting finger in $\mathrm{X}$ and $\mathrm{Z}$ direction can find out.

\section{Determination of picking and planting position of rice seedlings}

$\mathrm{M}$ indicates a point from where seedling finger pick the seedlings from the seedling tray which is $39.5 \mathrm{~cm}$ away from A point $(0,0)$. At A point, link was fixed at an angle $60^{\circ}$ with horizontal. $\mathrm{R}$ is a point from where seedling finger will enter into the soil and $\mathrm{P}$ point indiactes the position of planting seedlings in the soil whichis $5 \mathrm{~cm}$ below the $\mathrm{R}$ point.In this experiment,it was found that the seedling finger travels $37 \mathrm{~cm}$ distance in $\mathrm{Z}$ direction and $12.5 \mathrm{~cm}$ in $X$ direction in every revolution of the crank. M, R, P and A, all these points are shown in Figure 5.

\section{Test in laboratory conditions}

The hand operated model was tested in laboratory condition, during the testingdifferent performance parameters were measured such as depth of planting, hill to hill spacing, number of seedlings per hill and visible damage; an average and standard deviation of these parameters are shown in Table 2 .

\section{Test in fieldconditions:}

The prototypesingle row rice transplater was tested in the puddled field size about $2 \times 2 \mathrm{~m}$. The different performance parameters were measured during the testing such as depth of planting, hill to hill spacing, number of seedlings per hill and visible damage; an average and standard deviation of these parameters are shown in Table 3. The result shows that the depth of planting varied from 4.6 to $6.12 \mathrm{~cm}$ which lies in recommended range 2 to $6 \mathrm{~cm}$ (Alam, Bak, Sultana, Ali and Islam, 2012) which is in acceptable range. On an average number of seedlings per hill found to be 3 which is in the acceptable range but it depends on the cross section area of the stem's seedlings and opening of the transplanting finger slot. 


\begin{tabular}{|c|c|c|c|c|c|}
\hline \multicolumn{7}{|c|}{ Table 1 Dimensions of the links of the transplanting mechanism } \\
\hline $\begin{array}{c}\text { Sr. } \\
\text { No. }\end{array}$ & Links & Symbols & $\begin{array}{c}\text { Thickness, } \\
\text { mm }\end{array}$ & Width, cm & Length, cm \\
\hline 1 & Crank & (PQ) & 6 & 3 & 16.5 \\
\hline 2 & Coupler & A = (QS) & 6 & 3 & 30 \\
\hline 3 & Follower & B = (SR) & 6 & 3 & 30 \\
\hline 4 & Fixed & C $=(\mathrm{PR})$ & 6 & 3 & 30 \\
\hline 5 & Coupler extension & (ST) & 6 & 3 & 10.7 \\
\hline
\end{tabular}

Table.2 Different performance parameters achieved in laboratory conditions

\begin{tabular}{|l|c|c|c|c|}
\hline $\begin{array}{l}\text { In Laboratory } \\
\text { condition }\end{array}$ & $\begin{array}{c}\text { Depth of } \\
\text { planting, cm }\end{array}$ & $\begin{array}{c}\text { Hill to hill } \\
\text { spacing, cm }\end{array}$ & $\begin{array}{c}\text { Visible } \\
\text { Damage }\end{array}$ & $\begin{array}{c}\text { Seedlings per } \\
\text { hill }\end{array}$ \\
\hline Average value & 5.57 & 14.36 & 0.18 & 2.91 \\
\hline S.D. & 0.23 & 0.38 & 0.05 & 0.35 \\
\hline
\end{tabular}

Table.3 Different performance parameters achieved in field conditions

\begin{tabular}{|l|c|c|c|c|}
\hline In field condition & $\begin{array}{c}\text { Depth of } \\
\text { planting, cm }\end{array}$ & $\begin{array}{c}\text { Hill to hill } \\
\text { spacing, cm }\end{array}$ & $\begin{array}{c}\text { Visible } \\
\text { Damage }\end{array}$ & $\begin{array}{c}\text { Seedlings per } \\
\text { hill }\end{array}$ \\
\hline Average value & 4.88 & 16.39 & 0.64 & 3.24 \\
\hline S.D. & 0.76 & 0.32 & 0.70 & 0.24 \\
\hline
\end{tabular}

Fig.1 Path travelled by coupler point

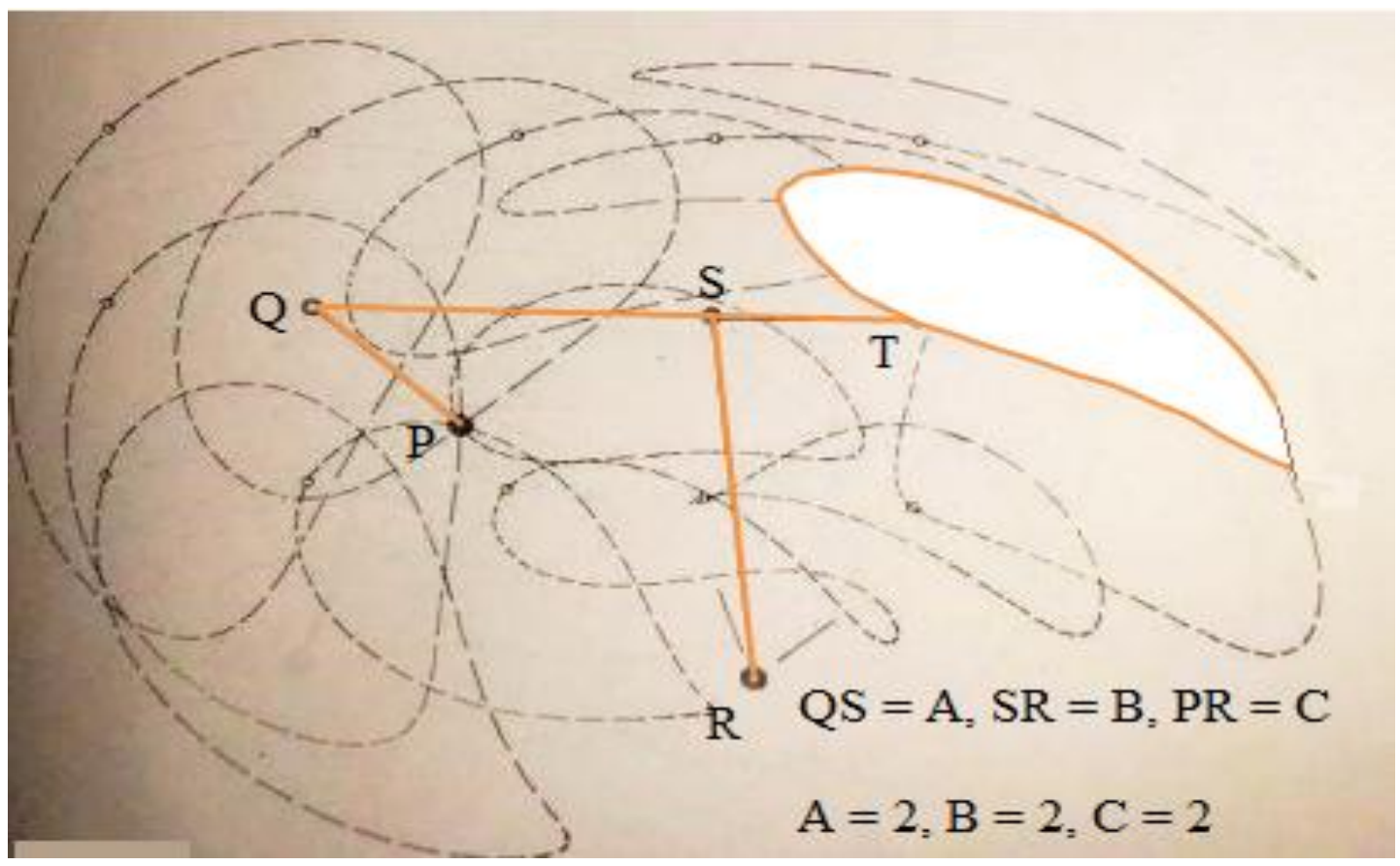




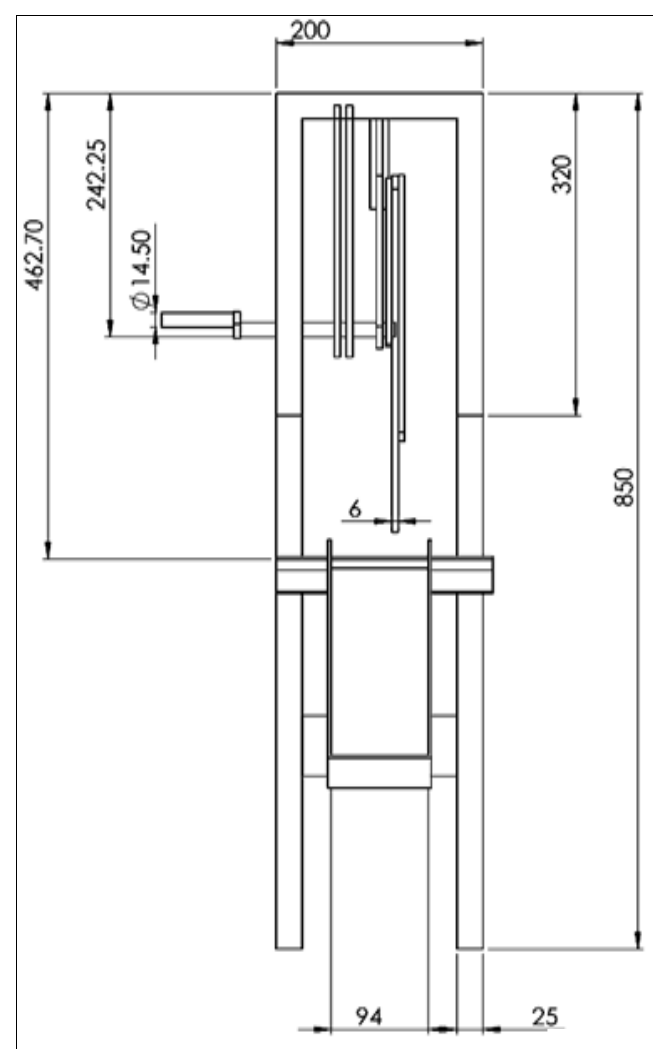

Fig. 2(a): Top view

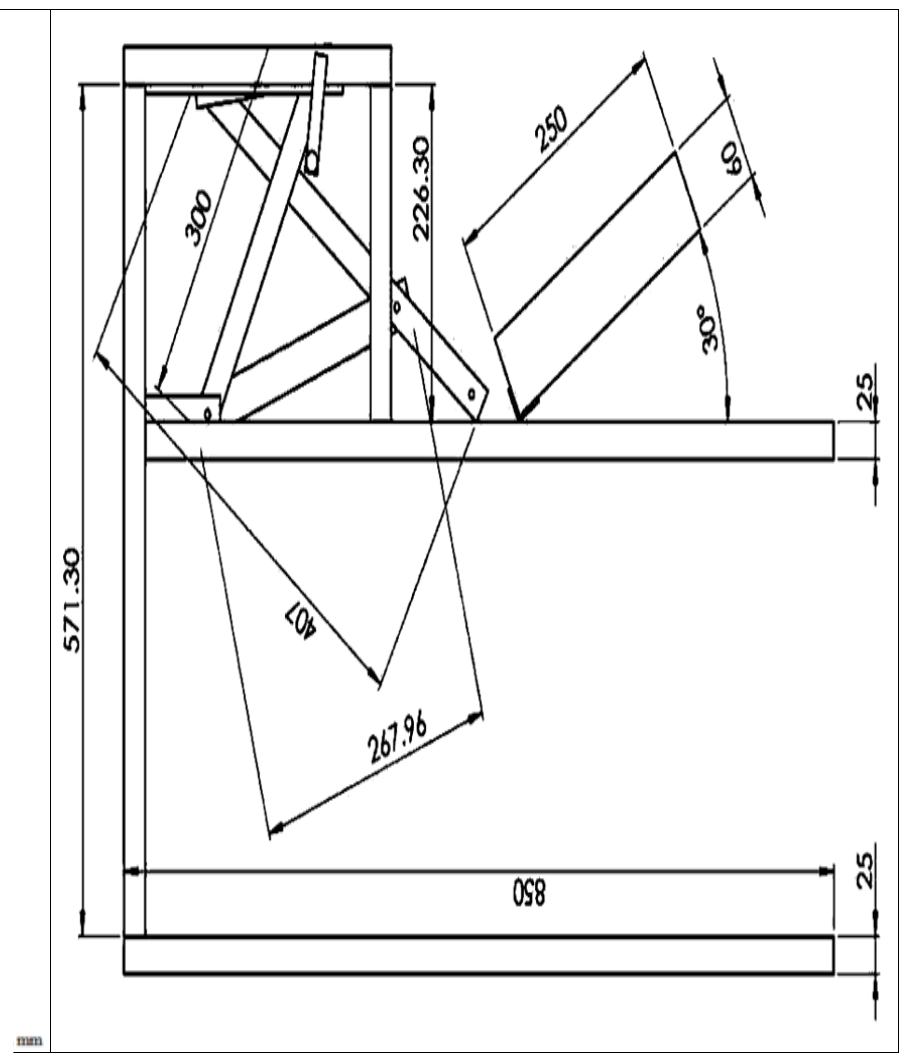

Fig. 2(b): Side view

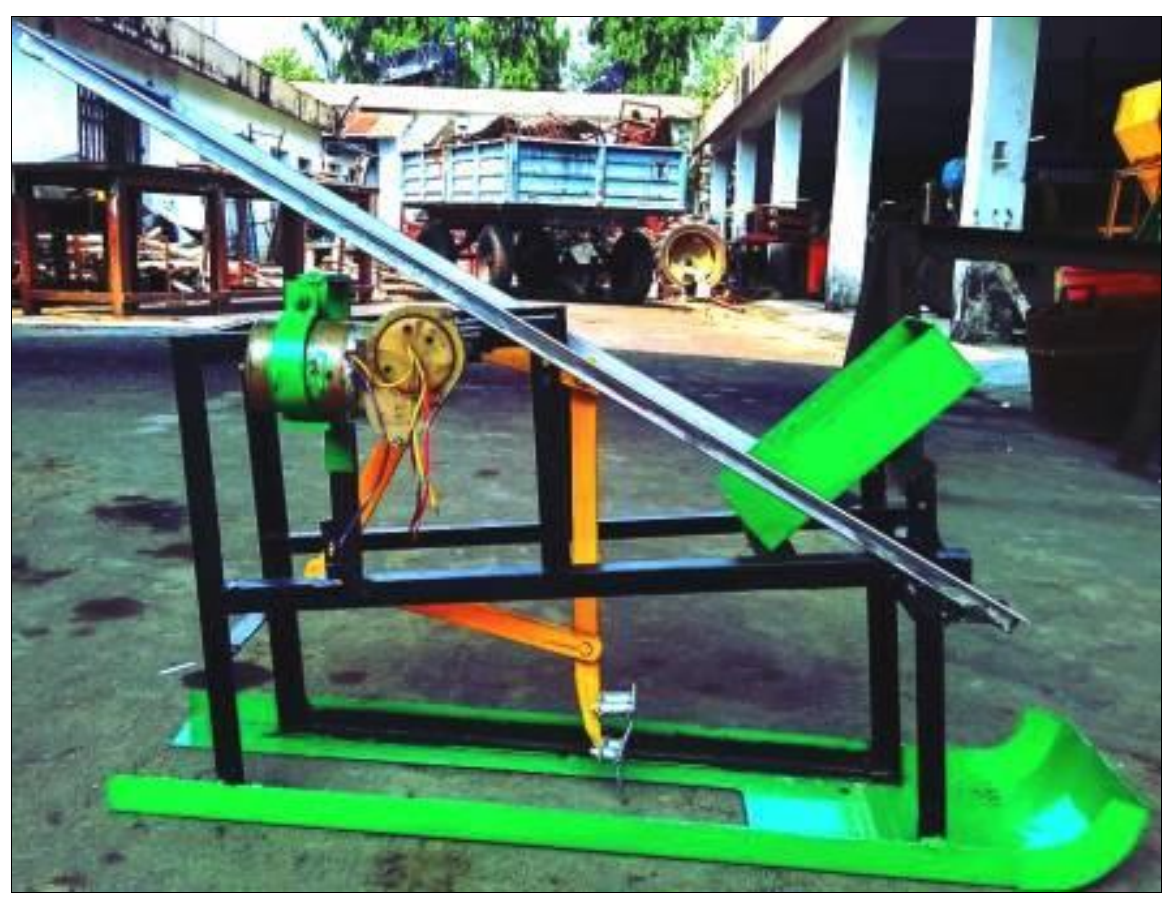

Fig.3 Prototype single row rice transplanter 


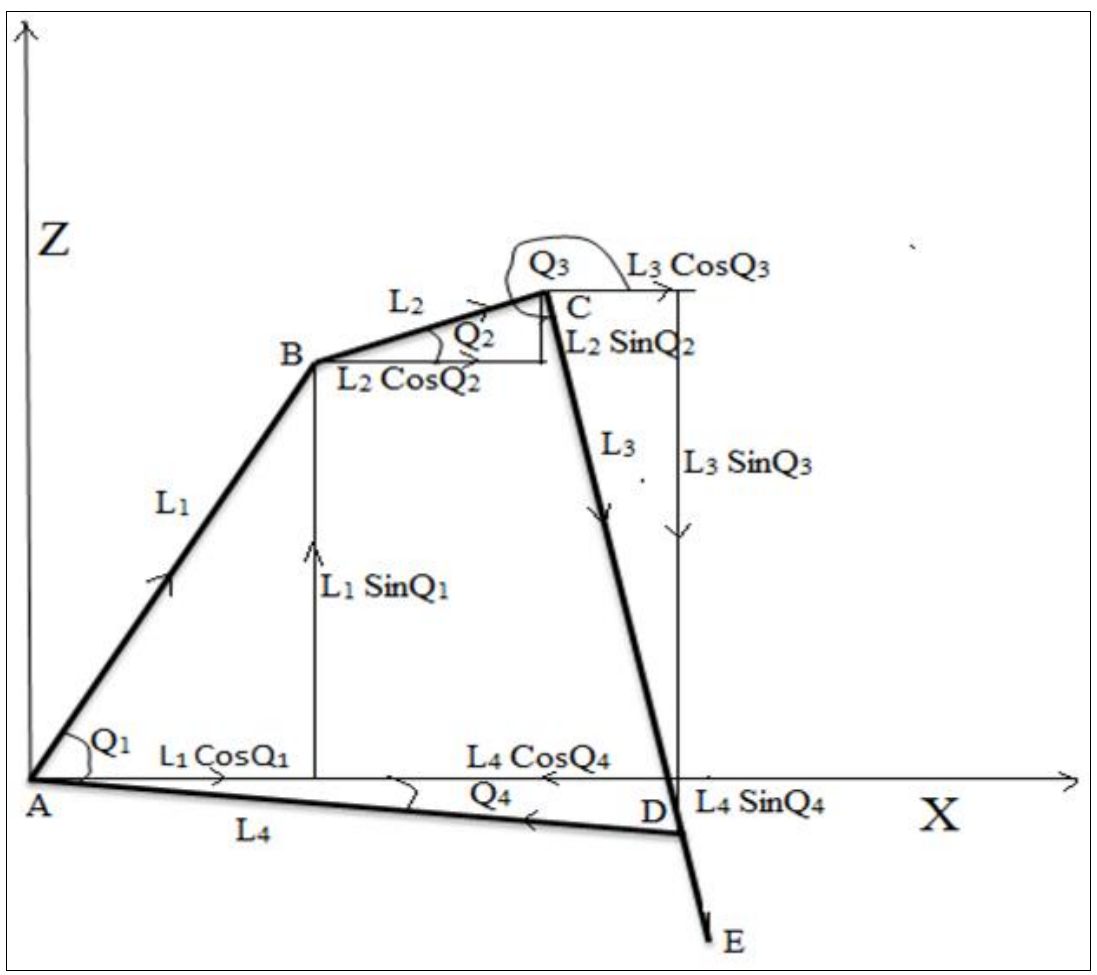

Fig.4 Vector diagram of developed four bar mechanism

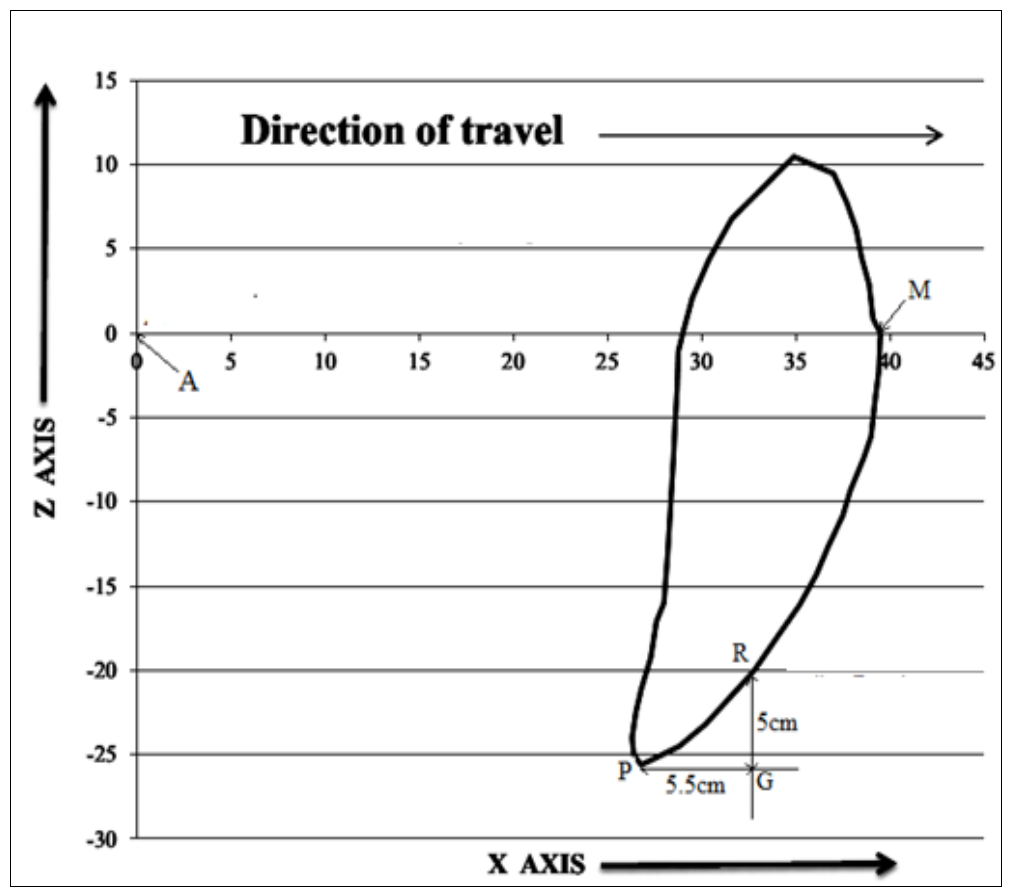

Fig.5 Path of movement of finger obtained by analytical method 
On an Average hill to hill spacing was found to be $16.39 \mathrm{~cm}$ which lies in the recommended range. The variation in hill to hill spacing is due to improper matching of the forward speed of rice transplanter. The visible damage found 0.70 in field conditions, which is little higher than that in the laboratory test.

In conclusion, the developed transplating mechanism was tested in laboratory as well as in field conditions, some specific conclusions were drawn.

When the developed transplanting mechanism was tested in laboratory conditions and then different parameters such as depth of planting, number of seedlings per hill, hill to hill spacing and visible damage were found to be $5.55 \mathrm{~cm}, 3$ seedlings, $14.43 \mathrm{~cm}$ and 0.05 per hill respectively. From all these performance parameters, it was concluded that model was working satisfactorily in laboratory.The prototypesingle row rice transplater was tested in the puddled field size about $2 \times 2 \mathrm{~m}$. The different performance parameters were measured like depth of planting, hill to hill spacing, number of seedlings per hill and visible damage were found to be $5.36 \mathrm{~cm}$, $18.03 \mathrm{~cm}, 4$ seedlings and 0.70 per hill respectively. The performance of developed transplating mechanism was found satisfactorily in laboratory as well as in field conditions.

This method will give alternative way to design the transplanting mechanism for power operarted rice transplanter and reduce complex contsruction design upto certain limit.

\section{References}

Alam, M. S., Baki, M. A., Sultana, M. S., Ali, K. J., and Islam, M. S. (2012). Effect of variety, spacing and number of seedlings per hill on the yield potentials of transplant aman rice. Int. J. Agr. and Agri, 2, 10-15.

Angeles, J., and Bernier, A. (1987).A general method of four-bar linkage mobility analysis. Journal of mechanisms, transmissions, and automation in design, 109(2), 197-203.

Atma, D., Pitoyo, Budiman, Joko, Rosmeika, Sulistiadji, Koes, and Sulistiadji (2006).Design and development of manual rice transplanters. J. Agric. Engg. Res., 43, pp. 350-357.

Datt, P. (1995). Development and Evaluation of Amanually Operated Rice Transplanter. Agricultural Engineering Today, 19(3and4), 21-26.

Garg, I. K., and Sharma, V. K. (1984). Design, development and evaluation of PAU riding type engine operated paddy transplanter using mat type seedlings. Proc. ISAE. SJC, 1(2), 7-63.

Goel, A. K., Behera, D., and Swain, S. (2008). Effect of sedimentation period on performance of rice transplanter. Agricultural Engineering International: CIGR Journal. Manuscript PM 07034. Vol. X.

Gurpude, R. R., Ashkhedkar, R. D., Handa, C. C., and Choudhary, S. K. (2012). Design, synthesis and simulation of four bar mechanism for wheels for climbing.International Journal of Computer Technology and Electronics Engineering (IJCTEE), 2(2), 218-220.

Hartenberg, R., and Danavit, J. (1964). Kinematic synthesis of linkages. New York: McGraw-Hill., Language: English, ISBN-10: 0070269106, pp. 187-188.

Kamble, P. K., Handa, C. C., and Zode, P. N. (2014). Generalized methodology of synthesis of four bar mechanism. International Journal of Mechanical Engineering and Robotics Research, 3(1), 160-165.

Manjunatha, M. V., Reddy, B. M., 
Shashidhar, S. D., and Joshi, V. R. (2009). Studies on the performance of self-propelled rice transplanter and its effect on crop yield. Karnataka Journal of Agricultural Sciences, 22(2), 385387.

Saggere, L., and Kota, S. (2001). Synthesis of planar, compliant four-bar mechanisms for compliant-segment motion generation. Journal of Mechanical Design, 123(4), 535-541.

Shahare, P.U. and Bhat, M.R., (2011). Development and performance evaluation of two row paddy transplanter, Internet J. Agric. Engg., 4 (1), pp. 103-105.

\section{How to cite this article:}

Jagjeet Singh. 2018. Development of a Transplanting Mechanism Model for Power Operated Rice Transplanter using Graphical Method. Int.J.Curr.Microbiol.App.Sci. 7(12): 298-305. doi: https://doi.org/10.20546/ijcmas.2018.712.036 